\title{
Tonic immobility in Japanese quail can reduce the probability of sustained attack by cats
}

\author{
R. K. R. THOMPSON, R. W. FOLTIN, R. J. BOYLAN, A. SWEET, \\ C. A. GRAVES, and C. E. LOWITZ \\ Franklin and Marshall College, Lancaster, Pennsylvania 17604
}

\begin{abstract}
In a two-choice experiment, cats (Felis domesticus) chose an active quail (Coturnix coturnix japonica) more often than a quail in tonic immobility (TI). In a second experiment, cats were individually presented with two active quail in an open field. Holding and biting by the cat, particularly about the neck, was necessary for inducing TI in a bird. Overall, the total time spent by a cat in stalking, attacking, and handling a bird was inversely related to the total time spent in TI by the bird. These results support the hypothesis that TI is a terminal defense mechanism elicited by predator contact. TI apparently eliminates the movement stimuli that sustain further attack.
\end{abstract}

Many invertebrate and vertebrate animals, upon release from brief physical restraint, do not attempt to escape but, instead, remain in an immobile state characterized by relative muscular hypertonicity, intermittent eye closure, and depressed heart rate (e.g., Maser \& Gallup, 1977; Nash, Gallup, \& Czech, 1976). This phenomenon has been labeled variously as death feigning, animal hypnosis, and, more recently, tonic immobility (TI) (Crawford \& Prestrude, 1977; Gallup, 1974).

A major theoretical interpretation of $\mathrm{TI}$ is that it functions as an adaptive terminal defensive reaction occurring in response to predatory attack (Gallup, 1977; Ratner, 1967). With rare exception (Francq, 1969; Sargeant \& Eberhardt, 1975), naturalistic observations supporting this viewpoint are anecdotal (e.g., Vogel, 1950). Francq (1969), investigating death feigning in opossums (Didelphis marsupialis), reported that all 25 animals "fully grabbed" by a domestic dog displayed TI. Unfortunately, the dog's reaction to TI was not documented, and, hence, Bragg's (1945) conclusion that TI is in fact not adaptive but, rather, is an abnormal fear-potentiated (i.e., "scared stiff"') response to predation cannot be simply dismissed by Francq's results. Perhaps the only convincing demonstration of the survival value of TI in a naturalistic study is Sargeant and Eberhardt's (1975) finding that 29 of $50(58 \%)$ ducks induced into TI when seized by a fox (Vulpes fulva) survived the initial attack.

Most of the experimental data interpreted as supporting the antipredator defense theory of TI comes from laboratory studies investigating the effects of

Reprint requests should be sent to the first author at Whitely Psychology Laboratories, Franklin and Marshall College, P.O. Box 3003, Lancaster, Pennsylvania 17604. such factors as predator distance and physical attributes on, for example, the duration of TI (e.g., Gallup, Nash, Donegan, \& McClure, 1971; Hennig, Dunlap, \& Gallup, 1976). However, all of these laboratory studies have simulated predation through the use of predator models (e.g., stuffed hawks and owls) and experimenter-induced TI, and, therefore, the evidence they provide for the antipredator defensive theory of TI is at best indirect. Although the simulation procedures have generated considerable important information about those aspects of predator models maintaining $\mathrm{TI}$, they have not, indeed cannot, provide answers to questions concerning the probability either of TI following a predatory attack or of a predator's response to TI should it occur. Yet, information about these latter aspects of predatorprey interactions is crucial if the functional role of TI is to be adequately evaluated experimentally in the laboratory.

The present study was carried out primarily to determine if, under laboratory conditions, TI would actually reduce the amount of attention focused on an animal by a predator. Also of interest was whether or not TI would be induced by an attacking animal in the laboratory, as has been demonstrated in the cited field studies.

Domestic cats (Felis domesticus) and Japanese quail (Coturnix coturnix japonica) were used as representative predators and prey, respectively, in both experiments. Cats have been used previously in laboratory studies of felid predatory behavior (e.g., Adamec, 1975; Biben, 1979), although the response of their prey was not focused upon. Experimenterinduced TI has been demonstrated previously in quail species (Benoff \& Siegel, 1976; Borchelt \& Ratner, 1973). Domestic cat predation on natural quail populations is well documented (Stoddard, 1931), and 
genetic analysis of TI in Japanese quail suggests prior natural selection as an adaptive trait (Benoff \& Siegel, 1976). Also, a photograph of a mosaic from ancient Pompeii depicting a cat preying upon a quail indicates that humans have observed the predator-prey relationship between these animals for at least 2,000 years (Leonard von Matt/Photo Researchers; published in the 1979, September, calendar of the American Museum of Natural History).

We were not insensitive to the fact that the design of the study necessitated the possible injury or death of live unanesthetized birds. We therefore submitted the rationale and design of the experiments to the Franklin and Marshall Psychology Department's research ethics committee for review and approval before carrying out the research.

\section{EXPERIMENT 1}

Movement is apparently the salient prey attribute that increases the probability of attack in a variety of different animals, including snakes, rodents, and carnivores (Eibl-Eibesfeldt, 1961; Fox, 1972; Herzog \& Burghardt, 1974; Leyhausen, 1979; Moyer, 1968; Van Hemel \& Colucci, 1973). According to Leyhausen (1979), prey movement and direction of movement are the only factors which innately release crouching, stalking, and catching actions in cats. An immobile prey animal is apparently liable to attack only from cats highly experienced in hunting.

Given that TI, like freezing (Blanchard \& Blanchard, 1972), minimizes the primary stimulation for attack, its presumed adaptiveness might depend upon the greater likelihood of a predator's terminating an attack on an animal in TI (Gallup, 1977). To test this notion, we first tested the preference of cats given a spatial choice between one unrestrained quail and another in TI. A similar procedure, involving cats and chickens, was used in an unpublished experiment, described briefly by Gallup (1974), in which the cats approached and stalked a mobile bird almost three times as often as they did a chicken in TI.

\section{Method}

Subjects. Four domestic cats (Felis domesticus) and 32 Japanese quail (Coturnix coturnix japonica) served as subjects. The adult cats were drawn from the Franklin and Marshall Psychology Department's cat colony and had served previously as subjects in simple visual and auditory learning experiments. The male and female quail were at least 15 weeks of age during testing. The birds had been raised in the psychology laboratories and had been used previously as subjects in an illness-induced aversion study (Foltin, 1978).

Apparatus. The triangular shaped testing arena was placed in a fluorescently lit $3 \times 3 \mathrm{~m}$ room that had tiled walls and floor and a suspended wire-mesh ceiling. The two side walls of the arena were made of 1-m-high heavy-duty corrugated cardboard supported by wooden braces. The wall between the test room and adjacent observation room formed the base of the arena. The distance from the base of the arena to its apex was $3 \mathrm{~m}$. An aluminum startbox was placed at the apex of the arena. A 1-m-high corrugated cardboard divider extended $1 \mathrm{~m}$ out from the center of the base wall into the arena. Animals in the arena were observed through a $1.2 \times 3.4 \mathrm{~m}$ one-way mirror set in the base wall $.58 \mathrm{~m}$ above the floor. Choice response latencies were recorded using an electronic (Lab-chron 1405) timer.

Procedure. Each of the four daily testing sessions consisted of four discrete trials separated by a 10 -min intertrial interval. Hence, a total of 16 trials were run. Each session was run between the hours of $4: 30$ and $6: 30$ p.m., about 6 to $8 \mathrm{~h}$ after the regular daily feeding of the cats with commercial cat chow. A different cat was used during each session to avoid possible habituation of the choice approach response resulting from removal of the birds from the cats after each trial. Also, new quail were used as prey subjects in each session.

At the start of each trial, the cat was placed into the startbox located at the apex of the testing arena. Two quail were then placed into the arena via two wall openings between the arena and adjoining observation room. One bird was put to the left and one to the right of the center divider. One bird was unrestrained and allowed to move about freely, but the other bird was in a state of TI induced by an experimenter's briefly restraining it on its side in the manner described by Gallup, Nash, and Wagner (1971). Spatial position of the two types of bird was balanced over trials. When the two birds were in position, the startbox was raised and the cat was allowed to enter the arena and approach one bird. Both the type of bird chosen and the choice response latency were recorded by the experimenters in the adjoining observation room. Immediately after one bird was attacked, the cat was enticed away from the birds, which were then retrieved from the arena. Attacked birds were then immediately sacrificed with chloroform to minimize any further suffering.

\section{Results and Discussion}

The unrestrained moving bird was chosen by the cats on 14 of the 16 trials. No one cat chose a bird in TI more than once. This proportion $(.875)$ of approaches to the moving bird differs significantly from chance $(z=3, p<.005)$. Mean choice response latencies on Trials 1 through 4 were $2.5,3.1$, 6.5 , and $23.2 \mathrm{sec}$, respectively. The mean for Trial 4 contained one deviant latency of $83.7 \mathrm{sec}$, which was obtained when one cat initially failed to leave the startbox.

The results demonstrate that TI clearly reduces the probability of a bird's being attacked by a cat when a moving bird is present. These results are also consistent with the earlier unpublished finding (described in Gallup, 1974) that cats approached and stalked moving chickens significantly more often than they did immobile birds. Both sets of results support the hypothesis that the adaptiveness of TI lies in its eliminating the salient movement stimulus that not only elicited but also sustained the approach response of cats.

\section{EXPERIMENT 2}

TI in the first experiment, as in other laboratory studies (e.g., Gallup et al., 1971), was induced by an experimenter and not by the cat. In this experiment, the cats initially encountered only moving birds. One aim was to confirm in the laboratory that TI, unlike freezing, appears as a terminal defensive reaction 
only after a bird actually is restrained physically by a cat. But, perhaps more importantly, we also wanted to determine if predator-induced TI, should it occur, inhibited continuation of an attack, as predicted by the antipredation defensive reaction interpretation of $\mathrm{TI}$ and suggested by the results of Experiment 1. Because it is unlikely that social quail would normally be alone when first attacked, two quail were used on each trial.

\section{Method \\ Subjects. The four cats used in the first experiment served again as predators, one cat per session. Thirty-two new quail were used as the prey subjects. A different pair of quail was used on each trial.}

Apparatus. Except for the removal of the center divider, the testing arena was the same as in the first experiment.

Procedure. Each of the four daily testing sessions consisted of four 4-min discrete trials separated by a 10 -min intertrial interval. At the start of each trial, a cat was placed in the startbox at the apex of the arena. Following the release of two unrestrained mobile quail into the arena, the cat was released from the startbox and timing of the 4-min trial was begun.

During each trial, the total time spent by the cat in stalking, attacking, and prey handling each bird was recorded. Stalking was defined as noncontact prey-oriented movements; attacks were rapid forward movements culminating in physical contact with a bird; and prey handling involved manipulation of a bird by the cat with its forepaws and/or mouth (cf. Biben, 1979). The number and location of cat bites during prey handling was recorded, as was the total time spent by each bird in TI. TI was defined as prey immobility following contact by the cat and was characterized by the bird's lying on its side or back with its legs stretched out rigidly and showing no response to prey handling or other stimulation. Freezing was defined as immobility occurring without actual contact by the cat and was characterized by the bird's standing motionless in a crouched "hunched" position.

At the end of each trial, the cat was enticed away from the birds, which were removed from the arena and sacrificed with chloroform.

\section{Results}

Two of the four cats did not attack or bite any of their respective eight prey birds but instead spent each trial simply following and stalking the two birds about the arena and occasionally nosing and lightly batting the birds with their forepaws. None of the birds on these eight trials went into TI. Instead, they attempted to escape by running away from the approaching cat and occasionally abruptly fluttering vertically into the air. In one instance, a bird froze in a corner of the arena for about $100 \mathrm{sec}$, during which the cat stalked and followed the other bird about the arena.

The other two cats not only stalked their respective prey quail, but also attacked, bit, and handled them. Also, TI was induced at least once in one bird of a pair on four of the eight trials, in both birds on three trials, and in neither bird on one trial. On this particular trial, one bird froze for all but about $5 \mathrm{sec}$ of the trial and the cat stalked, but did not attack, the remaining bird.
After TI was induced in a bird, the cat would leave it to stalk the remaining moving bird. A bird would be reattacked if it came out of TI during a trial. In one case, a bird was reattacked, killed, and partially eaten after it came out of TI and moved while the second bird was still in TI. Of the total 18 separate times that TI induction was observed, it occurred 9 times following a neck bite, 7 times following prey handling about the head, twice following a back bite, and never following a wing bite or prey handling of the nonneck parts of the bird's body. There was considerable individual variability both in the time spent by the two cats in preying upon (i.e., stalking, attacking, and handling) each bird (mean $=93.6 \mathrm{sec}$, $\mathrm{SD}=76.02 \mathrm{sec}$, range $=5$ to $200 \mathrm{sec}$ ) and in $\mathrm{Tl}$ durations recorded for the quail (mean $=80.3 \mathrm{sec}$, $\mathrm{SD}=85.5 \mathrm{sec}$, range $=0$ to $217 \mathrm{sec})$. A Pearson product-moment correlation between cumulative TI duration per trial for each bird and the total time it was preyed upon by the cat was significant $(\mathrm{r}=$ $-.71, \mathrm{p}<.01$ ). In other words, the more time a bird spent in TI during a trial, the less time it was preyed upon.

\section{Discussion}

The results of this experiment demonstrate that TI does occur in response to attack. The birds' initial response to an approaching cat was to flee. Freezing was also observed on occasion before actual contact. However, mere physical contact, such as paw-batting of a bird by a cat, was not sufficient to induce TI in a bird. TI was observed only in those cases in which a cat's behavior culminated in holding and biting, particularly biting about the neck region. This pattern of responses by the birds, especially the association between TI induction and the locus of the normal felid predatory bite (Ewer, 1973), confirms that TI is a terminal defensive reaction that occurs only after other defenses have failed but the animal has survived the initial contact (cf. Ratner, 1976; Rovee, Kaufman, \& Collier, 1977). The probability of survival following the initial attack may be affected by other factors, such as the cat's hunger and past predatory experience (Biben, 1979; but cf. Polsky, 1975).

Another major finding of this experiment is the inverse relationship between TI duration and contact with the cat. This finding provides strong experimental evidence that TI is effective in reducing the probability of sustained attack and handling, as indicated by the results of our first experiment, by eliminating the movement stimuli that elicit attack by the cat. The observation that once TI was induced a cat left a bird to stalk the remaining moving bird lends some empirical credence to historical and recent anecdotes in which Dr. Livingston and Legault were dropped by an attacking lion and a polar bear, respectively, in order to attack another person who was 
moving (Greenwood, 1885, and Legault, 1976, as cited in Mountjoy, 1980).

One might argue that, in a natural setting, alternative, moving birds might not be readily available to entice the cat away from a captured immobile bird as was the case in the present experiment. Members of a quail flock likely would rapidly flee and disperse in response to the cat's initial attack. However, Leyhausen's (1979) observations that cats invariably walk away temporarily from captured prey as soon as it stops moving (also see Biben, 1979) suggests that alternative, moving prey might not be a necessary condition for an animal in TI to be left with an increased opportunity to escape.

The considerable variability in TI duration obtained in the present experiment is consistent with similar findings in studies of experiment-induced TI in various species (e.g., Gallup et al., 1971). This similarity in the birds' TI responses across studies encourages the view that the data obtained using simulated predation procedures are not artificial but do accurately reflect the functional relationships between TI and predation.

The individual variations in the cats' responses to the birds is consistent with similar observations made in studies of predatory behavior in cats by both Adamec (1975) and Biben (1979). The behavior of the two cats that stalked, pawed, but did not attack and bite their birds is reminiscent of the defensiveattack and predatory-play behaviors described by Adamec (1975) and Biben (1979), respectively. The failure of two of our four cats to attack and bite birds, therefore, is possibly attributable to a conflict between a fear of the unfamiliar birds and movementinduced attack tendencies which might have been resolved had the cats had greater experience with the birds. However, these cats did attack birds in Experiment 1 . Therefore, it may be more parsimonious to interpret the results with two moving prey (Experiment 2) in terms of an approach-approach conflict, which reduces the probability of attack on any one bird.

In summary, the results of the present study confirm that movement is the primary salient stimulus eliciting attack by cats. More importantly, we believe that the results provide the first clear evidence from a laboratory study that TI occurs in response to attack and, once induced, reduced the probability of sustained attack. These results therefore provide strong empirical support for the theory that TI is a terminal defensive reaction that may well have adaptive significance in the context of predator-prey interactions.

\section{REFERENCES}

Alsmer, R. The behavioral bases of prolonged suppression of predatory at ack in cats. Aggressive Behavior, 1975, 1, 297-314.
Benoff, F. H., \& Siegel, P. B. Genetic analysis of tonic immobility in young Japanese quail (Coturnix coturnix japonica). Animal Learning \& Behavior, 1976, 4, 160-162.

Biben, M. Predation and predatory play behavior of domestic cats. Animal Behaviour, 1979, 27, 81-94.

Blanchard, R. J., \& Blanchard, D. C. Defensive reactions in the albino rat. Learning and Motivation, 1971, 2, 351-362.

Borchelt, P. L., \& Ratner, S. C. Development of freezing and immobility, predator defenses, in the bobwhite quail (Colinus virgianus). Behavioral Biology, 1973, 8, 83-92.

BragG, A. N. Notes on the psychology of frogs and toads. Journal of General Psychology, 1945, 32, 27-37.

Crawford, F. T., \& Prestrude, A. M. (Eds.). Animal hypnosis: Research and theory. Psychological Record, 1977, 27, Special Issue.

Eibl-Eibesfeldt, I. The interaction of unlearned behavior patterns and learning in mammals. In J. F. Delafresnaye (Ed.), Brain mechanisms and learning. Oxford: Blackwell, 1961.

EwE R, R. F. The carnivores. Ithaca, N.Y: Cornell University Press, 1973.

Foltin, R. W. The effects of previous experience on the development of illness-induced aversions in Japanese quail. Unpublished senior thesis, Frank lin and Marshall College, 1978.

Fox, M. W. Socio-ecological implications of individual differences in wolf litters: A developmental and evolutionary perspective. Behaviour, 1972, 35, 298-313.

FrancQ, E. N. Behavioral aspects of feigned death in the opossum (Didelphia marsupialis). American Midland Naturalist, 1969, 81, 556-568.

Gallup, G. G., JR. Animal hypnosis: Factual status of a fictional concept. Psychological Bulletin, 1974, 81, 836-853.

Gallup, G. G., JR. Tonic immobility: The role of fear and predation. Psychological Record, 1977, 27, 41-61.

Gallup, G. G., Jr., Nash, R. F., Donegan, N. H., \& McClure, M. K. The immobility response: A predator-induced reaction in chickens. Psychological Record, 1971, 21, 513-519.

Gallup, G. G., Jr., Nash, R. F., \& Ellison, A. L., Jr. Tonic immobility as a reaction to predation: Artificial eyes as a fear stimulus for chickens. Psychonomic Science, 1971, 23, 79-80.

Gallup, G. G., Jr., Nash, R. F., \& Wagner, A. M. The tonic immobility reaction in chickens: Response characteristics and methodology. Behavior Research Methods \& Instrumentation, 1971, 3, 237-239.

Hennig, C. W., Dunlap, W. P., \& Gallup, G. G., Jr. Effect of defensive distance and opportunity to escape on tonic immobility in Anolis carolinensis. Psychological Record, 1976, 26, 313-320.

Herzog, H. A., Jr., \& Burghardt, G. M. Prey movement and predatory behavior of juvenile western yellow-bellied racers, Coluber constrictor mormon. Herpetologica, 1974, 30, 285-289.

LEYHAUSEN, P. Cat behavior: The predatory and social behavior of domestic and wild cats. New York: Garland STPM Press, 1979.

Maser, J. D., \& Gallup, G. G., JR. Tonic immobility and related phenomena: A partially annotated, tricentennial bibliography, 1636-1976. Psychological Record, 1977, 27, 177-217.

Mountsoy, P. T. An historical approach to comparative psychology. In M. R. Denny (Ed.), Comparative psychology: An evolutionary analysis of animal behavior. New York: Wiley, 1980.

Moyer, K. E. Kinds of aggression and their physiological basis. Communications in Behavioral Biology, 1968, 2, 65-87.

Nash, R. F., Gallup, G. G., Jr., \& Czech, D. A. Psychophysiological correlates of tonic immobility in the domestic chicken (Gallus gallus). Physiology \& Behavior, 1976, 17, 413-418.

Polsky, R. H. Hunger, prey feeding and predatory aggression. Behavioral Biology, 1975, 13, 81-93.

Ratner, S. C. Comparative aspects of hypnosis. In J. E. Gordon (Ed.), Handbook of clinical and experimental hypnosis. New York: Macmillan, 1967.

Ratnk: R. S. C. Animals' defenses: Fighting in predator-prey relations. In P. Pilner, T. M. Alloway, \& L. Krames (Eds.), 
Advances in the study of communication and affect: $I I$. Nonverbal communication of aggression. New York: Plenum Press, 1976.

Rovee, C. K., Kaufman, L. M., \& Collier, G. H. Components of predation defense behavior in chickens: Evidence for endogenous rhythmicity. Physiology \& Behavior, 1977, 19, 663-671.

Sargeant, A. B., \& Eberhardt, L. E. Death feigning by ducks in response to predation by red foxes (Vulpes fulva). American Midland Naturalist, 1975, 94, 108-119.
STOdDARD, H. L. The bobwhite quail: Its habits, preservation, and increase. New York: Scribners, 1931.

Van Hemel, P. E., \& Colucci, V. M. Effects of target movement on mouse-killing by rats. Journal of Comparative and Physiological Psychology, 1973, 85, 105-110.

VogEL, H. H. Observations on social behavior in turkey vultures. $A u k, 1950,67,210-216$.

(Received for publication October 29, 1979; revision accepted July 17,1980 .) 